\title{
VIRŠUTINĖS PASAITO ARTERIJOS SINDROMAS. KLINIKINIS ATVEJIS
}

\author{
Rima Lukoševičienė, Laima Krajevienė, Neringa Taparauskaitė, Ernestas Krasauskas \\ Kauno klinikiné ligoniné
}

Raktažodžiai: pasaito arterija, dvylikapirštė žarna, obstrukcija, Wilkie sindromas.

\begin{abstract}
Santrauka
Viršutinès pasaito arterijos sindromas (VPAS) - tai simptomų kompleksas, kurị sukelia viršutinè pasaito arterija, išoriškai spausdama dvylikapirštès žarnos trečiają dalị. Bendrasis sergamumas šiuo sindromu nèra aiškus, tačiau nustatomas $0,013 \%-0,3 \%$ visu pacientų, tiriamų dèl žarnyno nepraeinamumo simptomatikos. Dažniausia šio sindromo priežastis yra ryškus kūno masès sumažejimas. Dèl dvylikapirštės žarnos suspaudimo išryškejja su žarnos obstrukcija susiję simptomai: pilvo skausmas, pykinimas, vèmimas, atsirandantys po valgio, ankstyvas sotumo jausmas, sumažèjęs apetitas. VPAS diagnozè patvirtinama pilvo organų KT arba MRT tyrimais. $\leq 25^{\circ}$ aortomezenterinio kampo nustatymas yra jautriausias rodiklis, pagrindžiantis VPAS diagnozę, ypač tada, kai aortomezenterinis atstumas yra $\leq 8 \mathrm{~mm}$. Dažniausiai VPAS gydomas konservatyviai, tačiau sunkiais atvejais prireikia chirurginio gydymo. $90 \%$ atvejų baigtis - visiškas pasveikimas.
\end{abstract}

\section{Ivadas}

VPAS metu sumažejus kampui tarp pilvinès aortos ir viršutinės pasaito arterijos spaudžiama dvylikapirštes žarnos trečioji dalis (1 pav.). Dèl dvylikapirštès žarnos suspaudimo išryškèja su žarnos obstrukcija susiję simptomai: pilvo skausmas, pykinimas, vėmimas, atsirandantys po valgio, ankstyvas sotumo jausmas, sumažejęs apetitas. Dažniausiai sindromo atsiradimas susijęs su kūno masès sumažèjimu, kai sumažeja riebalinio audinio sankaupa apie viršutinę pasaito arteriją, rečiau jis atsiranda po operacinès skoliozės korekcijos, kairiosios nefrektomijos. Galima ịgimta forma, nulemta anatominių veiksnių - Treitz'o raiščio padèties, viršutinès pasaito arterijos atsišakojimo vietos. Dẻl nespecifinio klinikinio pasireiškimo svarbu atmesti kitas galimas simptomų priežastis. Sindromo diagnostika paremta obstrukcijos požymių nustatymu rentgenologiniais tyrimais (apžvalgine pilvo organų rentgenograma, rentgenokontrastiniu tyrimu) ir dvylikapirštės žarnos suspaudimo nustatymu pilvo organų KT, MRT angiografijoje ịvertinant aortomezenterinị kampą ir atstumą. Gydymui svarbi pakankama mityba (jei reikia - enteriné per nazojejuninį zondą arba parenterinė), tinkama padetis po valgio, skrandžio dekompresija nazogastriniu zondu, taip pat skiriamas metoklopramidas. Kartais reikia chirurginio gydymo. Pateikiamas pacientės, kuriai nustatytas viršutinès pasaito arterijos sindromas, klinikinis atvejis. Literatūros apžvalgoje aptariamos galimos sindromo atsiradimo priežastys, klinikinio pasireiškimo ypatumai, galimos gydymo taktikos. VPAS aktualus, nes dažnai nediagnozuojamas dèl būdingų nespecifinių simptomų. Laiku nustatyta diagnozė ir gydymas svarbūs norint išvengti išsekimo, elektrolitų disbalanso, dehidratacijos ir kitų galimų pasekmių (1 pav.).

\section{Klinikinis atvejis}

L.L., 33 metų moteris, atvykusi į Kauno klinikinès ligoninès (KKL) suaugusiujų prièmimo skyrių, skundèsi pilvo skausmu viršutinėje pilvo dalyje, atsirandančiu po valgio, tuštinimusi skystomis išmatomis, protarpiais atsirandančiu pykinimu. Minèti simptomai palaipsniui progresavo apie du tris ménesius. Prieš kelias savaites pacientei pilvo skausmai pradèjo dažniau kartotis, pailgèjo jų trukmè, skausmai atsirasdavo po valgio praejjus 1-3 valandoms, jie niekur neplisdavo, nesteroidiniai vaistai nuo uždegimo jų nemalšindavo, praeidavo savaime po 4-6 valandų. Dèl minètų skundų paciente kreipèsi $i$ Lietuvos sveikatos mokslų universiteto Kauno klinikų skubios pagalbos skyrių, tačiau atlikus kraujo biocheminius tyrimus, viršutinio pilvo aukšto echoskopiją bei ezofagofibrogastro duodenoskopiją (EFGDS), skausmų priežastis nepaaiškejjo. Iš gyvenimo anamnezès patikslinta, kad pacientè per trumpą laiką numete $7 \mathrm{~kg}$ svorio, yra sirgusi opalige, dvylikapiršteje žarnoje buvo nustatytos 4 opos, skrandžio vėžiu sirgo senelis, yra du kartus gimdžiusi, atliktas cezario pjūvis. Paciente stacionarizuota ị KKL Vidaus ligų diagnostikos skyrių.

Hospitalizavimo metu pacientès būklè patenkinama, glei- 
vinès ir oda blyškios. Liežuvis su apnašu. Širdies veikla ritmiška, ŠSD - 82 k./min., AKS 116/74 mmHg. Plaučiuose alsavimas vezikulinis be karkalų. KD - $22 \mathrm{k}$./min. Pilvas minkštas, skausmingas epigastriume, abipus po šonkauliu lankais. Išklausoma skambi peristaltika keturiuose pilvo kvadrantuose. Pilvaplèvès dirginimo simptomas neigiamas. Kojose edemų nèra. Atlikti laboratoriniai tyrimai: bendras kraujo tyrimas, C-reaktyvinis baltymas, bendras bilirubinas, tiesioginis bilirubinas, netiesioginis bilirubinas, glikemija, kreatininas, kalis, kepenų fermentai - norma. P-amilazė padidejusi - $124 \mathrm{U} / 1$, tiriant dinamikoje $115 \mathrm{U} / 1 ; 144 \mathrm{U} / 1$. Atlikta EFGDS, nustatyta $I^{\circ}$ nefiksuota ašinè diafragminè išvarža, duodenogastrinis refliuksas, dvylikapirštes žarnos stormens randinè deformacija. Atlikta pilvo viršutinio aukšto echoskopija - be organinès patologijos. Atlikta fibrokolonoskopija (FKS), jos metu apžiūrèta žarna iki aklosios žarnos dugno, organinès patologijos nenustatyta. Atliktas kontrasto slinkimo žarnynu rentgenologinis tyrimas (2 pav.): nustatyta horizontaliosios dvylikapirštès dalies obstrukcija bei aukš-

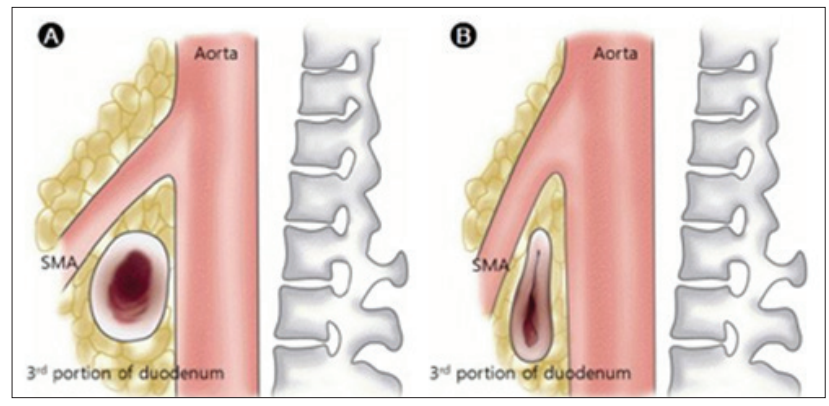

1 pav. A - aortomezenterinis kampas normos atveju. B - aortomezenterinis kampas sergant VPAS [1].

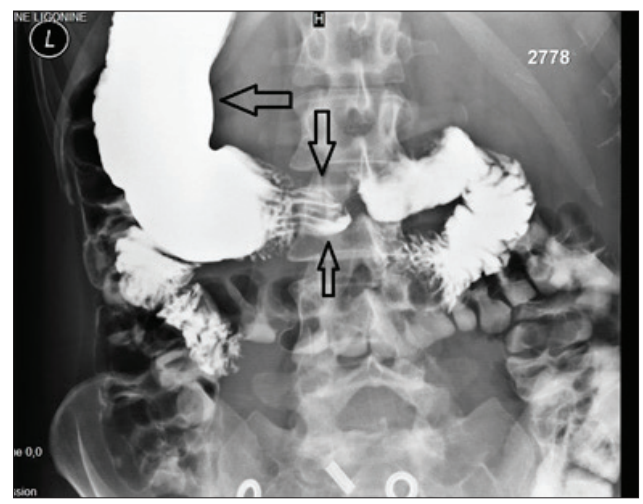

2 pav. Dvylikapirštės žarnos trečiosios dalies obstrukcija su staigiu praeinamumo nutrūkimu ir aktyvia peristaltika. Nusileidžiančios dvylikapirštès dalies dilatacija. čiau esančios žarnos dilatacija, pagal esamą rentgenologini vaizdą panašu ị viršutinès pasaito arterijos sindromą, sukeliantį evakuacijos sutrikimus dvylikapirštės žarnos spindžiu.

Atliktas pilvo organų KT tyrimas (3, 4 pav.), be aiškiai matomos organinès patologijos, galima įtarti aortomezenterinio kampo sumažèjimą, tikslingas su kraujagyslių kontrastavimu atliktas pilvo KT.

Pacientei skirtas konservatyvus gydymas antispazmolitikais, anticholinerginiais bei motoriką reguliuojančiais vaistais, netaikytas tuščiosios žarnos zondavimas bei chirurginès intervencijos. Taikant konservatyvų gydymą bei maitinantis specialiosios medicininès paskirties dietiniu maistu, pacientei nebeatsirasdavo priepuolinio pobūdžio skausmų. Po penkių konservatyvaus gydymo dienų paciente išrašyta iš stacionaro. Ambulatoriškai pacientė tęsė konservatyvų gydymą bei laikèsi paskirtos dietos. Atlikti rekomenduoti tyrimai dèl autoimuninès kilmès pankreatito buvo neigiami. Atliktas pilvo organų magnetinis rezonansas su Omniscan $0.5 \mathrm{mmol} /$ $\mathrm{ml} 15 \mathrm{ml}$ kontrastavimu - be organinès patologijos.

Pacientei L.L skirtas ilgalaikis konservatyvus gydymas,

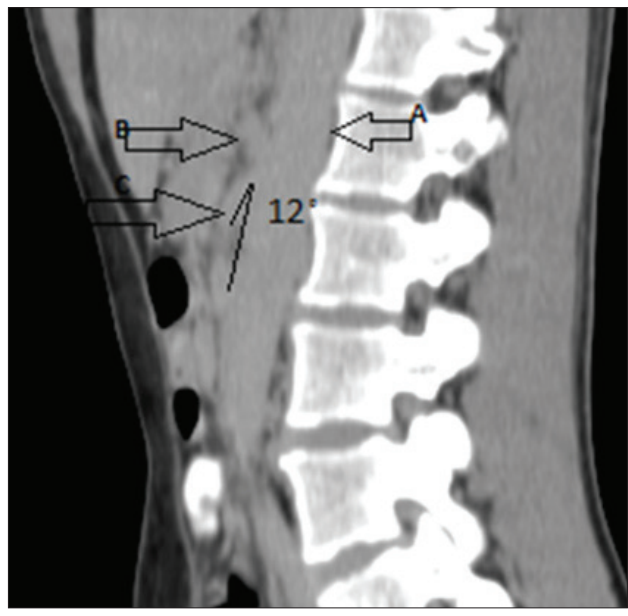

3 pav. A - pilvinè aorta, B- pilvinis kamienas, $\mathrm{C}-$ viršutinè pasaito arterija

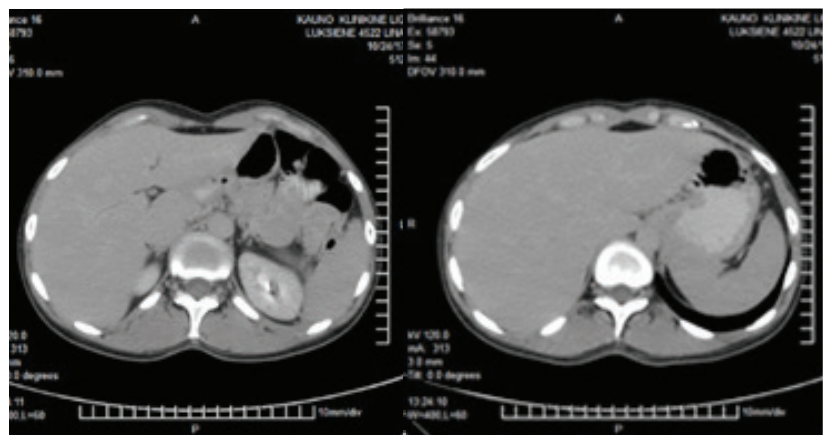

4 pav. Dvylikapirštės žarnos dilatacija 
1 lentelė. Viršutinès pasaito arterijos sindromo diferencinė diagnostika [2]

\begin{tabular}{|c|c|}
\hline Organinès kilmės & $\begin{array}{l}\text { Skrandžio opa } \\
\text { Dvylikapirštės žarnos opa } \\
\text { Pankreatitas } \\
\text { Ūmus apendicitas } \\
\text { Ūmus cholangitas } \\
\text { Ūmus cholecistitas } \\
\text { Tulžies pūslès akmenligè ir kepenų kolika } \\
\text { Ūmus pielonefritas } \\
\text { Ketoacidozinė būklė } \\
\text { Vidurių užkètèjimas } \\
\text { Divertikulitas } \\
\text { Dismenorèja } \\
\text { Uždegiminė mažojo dubens liga } \\
\text { Kiaušidės apsisukimas } \\
\text { Endometriozė } \\
\text { Uždegiminės žarnų ligos } \\
\text { Ūmi pasaitinių arterijų išemija } \\
\text { Kolagenozės }\end{array}$ \\
\hline Neorganinės kilmės & $\begin{array}{l}\text { Nervinès kilmės anoreksija } \\
\text { Nervinès kilmės bulimija } \\
\text { Dirgliosios žarnos sindromas }\end{array}$ \\
\hline
\end{tabular}

laikantis dietos, palaipsniui ịvedant didesnès energetinės vertès maistą, taikant svorio kontrolę. Praẻjus dviem savaitėms, pacientei skausmai nesikartojo, priaugo $2 \mathrm{~kg}$ svorio. Toliau tęsiamas konservatyvus gydymas, pacientès būklè stebima dinamikoje (1, 2 lentelè).

\section{Literatūros apžvalga}

VPAS - tai simptomų kompleksas, kurị dažniausiai sąlygoja riebalų sankaupos, esančios tarp viršutinės pasaito arterijos ir trečiosios dvylikapirštės žarnos dalies, netektis [4]. Sumažejus riebalinio audinio sankaupai apie viršutinę pasaito arteriją, kampas tarp aortos ir viršutinės pasaito arterijos smailèja, trečioji dvylikapirštės žarnos dalis tampa išoriškai spaudžiama viršutinès pasaito arterijos [5]. Kampas, susidarantis tarp aortos ir viršutinès pasaito arterijos atsišakojimo vietos, îprastai būna nuo $25^{\circ} \mathrm{iki} 60^{\circ}$, atstumas tarp atitinkamų arterijų - nuo $10 \mathrm{~mm}$ iki $28 \mathrm{~mm}$ [6]. Abu parametrai, pasireiškiant šiam sindromui, atitinkamai sumažèja iki $6^{\circ}-15^{\circ}$ ir 2 $\mathrm{mm}-8 \mathrm{~mm}$ [4]. Dažniausia šio sindromo priežastis: ryškus kūno masès sumažejjimas, galimai dèl ligos, pvz., anoreksijos, laikantis griežtų dietų [7]. Retesnès priežastys: skoliozès chirurginio gydymo komplikacija, igimtos priežastys: pvz., igimtas Treitz'o raiščio sutrumpėjimas, žemesnis viršutinès pasaito arterijos atsišakojimas [8].

Pirmą kartą viršutinės pasaito arterijos sindromą aprašè austrų profesorius C. F. von Rokitansky 1861 metais, vėliau D. Wilkie pateikè detalesni sindromo aprašą ir gydymo galimybes [4], todèl jis dar vadinamas Wilkie sindromu.
2 lentelė. Viršutinès pasaito arterijos sindromo diagnostikos kriterijai [3]

\begin{tabular}{|l|}
\hline $\begin{array}{l}\text { Dvylikapirštės žarnos trečiosios dalies obstrukcija su staigiu } \\
\text { praeinamumo nutrūkimu ir aktyvia peristaltika, nustatyta tiriant } \\
\text { kontrasto slinkimo žarnynu rentgenologiniu tyrimu. }\end{array}$ \\
\hline $\begin{array}{l}\text { Aortomezenterinis kampas } \leq 25^{\circ} \text {, aortomezenterinis astumas } \leq \\
8 \mathrm{~mm} \text {, atlikus pilvo organų KT su kraujagyslių kontrastavimu. }\end{array}$ \\
\hline $\begin{array}{l}\text { Aukšta dvylikapirštės žarnos fiksacija dèl Treitz'o raiščio trum- } \\
\text { pumo, nenormaliai žema viršutinės pasaito arterijos atsišakojimo } \\
\text { vieta bei kitos viršutinès pasaito arterijos anomalijos nustatytos } \\
\text { atlikus diagnostinę - gydomąą laparotomiją. }\end{array}$ \\
\hline
\end{tabular}

Bendrasis sergamumas šiuo sindromu nèra aiškus. Būdingas kontrastinès medžiagos kaupimasis viršutinėje virškinimo trakto dalyje, leidžiantis įtarti ši sindromą pasireiškia 0,013\% - 0,3 \% visų pacientų, tiriamų dèl žarnyno nepraeinamumo simptomatikos [9].

Dèl dvylikapirštès žarnos suspaudimo išryškèja su žarnos obstrukcija susiję simptomai: pilvo skausmas, pykinimas, vėmimas, atsirandantys po valgio, ankstyvas sotumo jausmas, sumažėjęs apetitas [10]. Pagrindinès komplikacijos, susijusios su šiam sindromui būdingų simptomų - pilvo skausmo, pykinimo, vėmimo atsirandimu pavalgius - pacientai negali normaliai maitintis, todèl netenka daug svorio, atsiranda elektrolitų disbalansas, metabolinė alkalozè, dehidracija [5].

VPAS diagnostika yra sudètinga dèl nespecifinių klinikinių išraiškų [11]. Svarbu atmesti kitas galimas plonųjų žarnų obstrukcijos priežastis (1 lentelè). Diagnostikai labai svarbūs duomenys apie paciento svorio kitimą, dietas, buvusias operacijas [12]. Pacientui atliekami instrumentiniai tyrimai: apžvalginè pilvo rentgenograma ir kontrasto slinkimo žarnynu rentgenologinis tyrimas [9]. Apžvalginèje pilvo rentgenogramoje būna matomi plonųjų žarnų nepraeinamumo požymiai, kontrasto slinkimo žarnynu rentgenologiniame tyrime matomas sulètėjęs kontrasto slinkimas, dažniausiai kontrastas sulaikomas trečiajame dvylikapirštės žarnos segmente [13]. Matomas dvylikapirštės žarnos, kartais ir skrandžio, išsipūtimas virš kliūties su ilgai užsilaikančia kontrastine medžiaga bei sulètèjęs kontrasto patekimas ị už kliūties esančią plonosios žarnos dalị [14]. Viršutinio pilvo aukšto echoskopija taip pat gali būti naudinga diagnozuojant VPAS [15]. Echoskopinio tyrimo metu vizualizuoti sumažèjusi kampą tarp pilvinès aortos ir viršutinès pasaito arterijos lengviau pacientui gulint ant šono [3]. Šiuo tyrimu taip pat galima pamatyti anatominius veiksnius, kurie gali lemti VPAS atsiradimą (Treitz'o raiščio padèti, viršutinès pasaito arterijos atsišakojimo vietą) [16]. Literatūroje yra duomenų, kad VPAS diagnostikai gali būti naudinga ir arteriografija, nes galima išryškinti viršutinę pasaito arteriją ties dvylikapirštės žarnos obstrukcijos vieta [3]. Vis dèlto pastaruoju 
metu VPAS diagnozė patvirtinama pilvo organų KT arba MRT angiografijos tyrimais [17]. $\leq 25^{\circ}$ aortomezenterinio kampo nustatymas yra jautriausias rodiklis, pagrindžiantis VPAS diagnozę, ypač tada, kai aortomezenterinis atstumas yra $\leq 8 \mathrm{~mm}$ [18] (2 lentelè). Dèl sumažejusio aortomezenterinio atstumo gali būti suspausta ir kairioji inksto vena, prasidèti jos trombozè arba išsiplèsti kolateralinès venos [7]. KT ir MRT tyrimai svarbūs ir tuo, kad jais galima ne tik nustatyti dvylikapirštès žarnos suspaudimą, bet ir pamatyti riebalinio audinio sankaupas bei jų sumažèjimą, Treitz'o raiščio, viršutinès pasaito arterijos padètị ir taip patikslinti sindromo priežastị, atmesti kitas galimas simptomų priežastis [8].

Dažniausiai VPAS gydomas konservatyviai, tačiau retais atvejais prireikia chirurginio gydymo [6]. Svarbu taikyti skrandžio ir žarnyno dekompresiją, ịvedant nazogastrinị zondą [12]. Būtina ịvertinti infuzinès terapijos ir elektrolitų balanso korekcijos poreiki, nes pacientams, sergantiems VPAS, dažnai nustatoma dehidratacija, hipokalemija, metabolinè alkalozė [5]. Jei VPAS yra nulemtas svorio netekimo ir riebalinio audinio apie viršutinę pasaito arteriją sumažèjimo, būtina užtikrinti pakankamą pacientų mitybą, galima vartoti specialios medicininès paskirties dietinį maistą [5]. Vis dèlto dažnai pacientai negali adekvačiai maitintis dèl pavalgius išryškẻjančių simptomų: pilvo skausmo, pykinimo, vẻmimo, tad kūno masẻ dar labiau sumažèja ir simptomai tampa dar ryškesni [4]. Literatūros duomenimis, simptomus po valgio gali palengvinti buvimas tam tikroje padėtyje: gulint ant kairiojo šono arba ant pilvo [11]. Jei tai nepadeda užtikrinti adekvačios mitybos, siūloma pereiti prie enterinès mitybos per nazojejunini zondą [12]. Kartais reikalinga parenterinè mityba [12]. Metoklopramidas taip pat naudigas mažinant VPAS simptomus [4]. Jei VPAS yra nulemtas svorio netekimo dèl nervinès anoreksijos, reikalinga psichiatro konsultacija [19]. Gydant konservatyviai, simptomai mažeja didejjant kūno masei, išskyrus atvejus, kai yra atvirkštinè peristaltika, riebalinis audinys nesikaupia dvylikapirštės žarnos suspaudimo vietoje arba yra ryškūs anatominiai veiksniai, lemiantys sindromo atsiradimą [5, 19].

Jei konservatyvus gydymas nèra efektyvus, pacientui taikomas chirurginis gydymas [6]. Prieš operaciją būtina įvertinti paciento mitybos būklę, tai svarbu sklandžiai pooperacinei eigai. Galimi operacinio gydymo variantai yra duodenojejunostomija (gali būti su arba be dvylikapirštès žarnos dalies rezekcija), kuri yra taikoma dažniausiai, Strong'o procedūra ir gastrojejunostomija [20]. Šias operacijas galima atlikti per laparotomini pjūvị arba laparoskopiškai [20]. Dažniausiai atliekamos duodenojejunostomijos metu dvylikapirštė žarna gali būti paliekama arba šalinama jos dalis, o proksimalinè tuščiosios žarnos dalis jungtimi šonas i šoną sujungiama su dvylikapiršte žarna [21]. Strong'o procedūros metu atidalinamas Treitz'o raištis, o dvylikapirštė žarna yra perkeliama dešiniau viršutinès pasaito arterijos [16]. Dar vienas operacinio gydymo variantas yra gastrojejunostomija, kurios metu suformuojama anastomozè šonas i šoną tarp skrandžio ir tuščiosios žarnos [11].

Pasirenkant chirurginį gydymą, svarbu ịvertinti kiekvieno metodo privalumus ir trūkumus bei individualią naudą kiekvienam pacientui. Strong'o procedūros metu išlaikomas žarnos vientisumas, tačiau maždaug $25 \%$ pacientų ši procedūra nesumažina VPAS simptomų [20]. Gastrojejunostomija atliekama retai dèl dažnų pooperacinių komplikacijų [21]. Geriausiai vertinami duodenojejunostomijos rezultatai, apie 90\% atvejų išnyksta VPAS simptomai [20]. Literatūros duomenimis, po operacijos rekomenduojama atlikti pakartotini rentgenokontrastinị tyrimą [16]. Jo metu vertinama, ar yra atstatytas normalus dvylikapirštės žarnos praeinamumas. Vèliau pacientai periodiškai stebimi dèl simptomų, varginusių iki operacijos, išnykimo ir svorio kitimų $[4,19]$.

\section{Išvados}

Viršutinės pasaito arterijos sindromas - reta aukšto žarnu nepraeinamumo priežastis. Kontrasto slinkimo žarnynu rentgenologinis tyrimas leidžia įtarti viršutinès pasaito arterijos sindromą. Konservatyvus viršutinès pasaito arterijos sindromo gydymas yra efektyvus gydymo būdas.

\section{Literatūra}

1. https://syndromespedia.com/wp-content/uploads/2015/10/ superior-mesentric-artery-syndrome-image.jpg

2. https://emedicine.medscape.com/article/932220-treatment

3. Scovell S, Hamdan A. Superior mesenteric artery syndrome. In: UpToDate, Post, TW (Ed), UpToDate, Waltham, MA, 2017.

4. Kumar R, Jaiswal G, Bhargava A, Kundu J. Superior mesenteric artery syndrome: diagnosis and management. Kathmandu Univ Med J 2016;14(55):288-291.

5. Chan DKH, Mak KSW, Cheah YL. Successful nutritional therapy for superior mesenteric artery syndrome. Singapore Med J 2012;53(11): 233-236.

6. Yao SY, Mikami R, Mikami S. Minimally invasive surgery for superior mesenteric artery syndrome: A case report. World J Gastroenterol 2015;21(45):12970-12975.

https://doi.org/10.3748/wjg.v21.i45.12970

7. Raman SP, Neyman EG, Horton KM, Eckhauser FE, Fishman EK. Superior mesenteric artery syndrome: spectrum of CT findings with multiplanar reconstructions and 3-D imaging. Abdom Imaging 2012;37(6):1079-88. https://doi.org/10.1007/s00261-012-9852-z

8. Yakan S, Calıskan C, Kaplan H, Deneclı AG, Coker A. Superior mesenteric artery syndrome: a rare cause of intestinal 
obstruction: diagnosis and surgical management. Indian J Surg 2013;75(2):106-110.

https://doi.org/10.1007/s12262-012-0423-x

9. Mandarry MT, Zhao L, Zhang C, Wei ZQ. A comprehensive review of superior mesenteric artery syndrome. Eur Sur 2010;42(5):229-236. https://doi.org/10.1007/s10353-010-0561-y

10. Jalilvand A, Fisichella PM. Superior mesenteric artery syndrome. Gastroenterologica Italiana 2014;46(9):859. https://doi.org/10.1016/j.dld.2014.03.021

11. Mathenge N, Osiro S, Rodriguez I, Salib C, Tubbs RS, Loukas M. Superior mesenteric artery syndrome and its associated gastrointestinal implications. Clin Anat 2014;29:1244-1252. https://doi.org/10.1002/ca.22249

12. Lee TH, Lee JS, Jo YJ, Park KS, Cheon JH, Kim YS, Jang JY, Kang YW. Superior mesenteric artery syndrome: where do we stand today? J Gastrointest Surg 2012;12:2203-2211. https://doi.org/10.1007/s11605-012-2049-5

13. Kaur A., Pawar N.C., Singla S., Mohi J.K., Sharma S. Superior mesentric artery syndrome in a patient with subacute intestinal obstruction: a case report. J Clin Diagn Res 2016;10(6):TD03TD05. https://doi.org/10.7860/JCDR/2016/19699.7932

14. Zaraket V, Deeb L.Wilkie's syndrome or superior mesenteric artery syndrome: fact or fantasy? Case Red Gastroenterol 2015;9:194-199. https://doi.org/10.1159/000431307

15. Unal B, Aktaş A, Kemal G. et al. Superior mesenteric artery syndrome: CT and ultrasonography findings. Diagn Interv Radiol 2005;11(2):90-5.

16. Cullis PS, Gallagher M, Subharwal AJ, Hammond P. Minimally invasive surgery for superior mesenteric artery syndrome: a case report and literature review. Scottish Medical Journal 2016;61(1):42-47. https://doi.org/10.1177/0036933015615261

17. Schauer SG, Thompson AJ, Bebarta VS. Superior mesenteric artery syndrome in a young military basic trainee. Mil Med 2013;178(3):398-399. https://doi.org/10.7205/MILMED-D-12-00415

18. Agrawal S, Patel H. Superior mesenteric artery syndrome. Surgery 2013;153:601-602. https://doi.org/10.1016/j.surg.2012.02.009

19. Sun Z, Rodriguez J, McMichael J, Walsh RM, Chalikonda S, Rosenthal RJ, Kroh MD, El-Hayek K. Minimally invasive duodenojejunostomy for superior mesenteric artery syndrome: a case series and review of the literature. Surg Endosc 2015;29:1137-1144.

https://doi.org/10.1007/s00464-014-3775-4

20. Pottorf BJ, Husain FA, Hollis Jr HW. Laparoscopic management of duodenal obstruction resulting from superior mesenteric artery syndrome. JAMA Surg 2014;149(12):1319-1322. https://doi.org/10.1001/jamasurg.2014.1409

21. Chang J, Boules M, Rodriguez J, Walsh M, Rosenthal R, Kroh M. Laparoscopic duodenojejunostomy for superior mesenteric artery syndrome: intermediate follow-up results and a review of the literature. Surgical Endoscopy 2017;31(3):1180-1185. https://doi.org/10.1007/s00464-016-5088-2

\section{SUPERIOR MESENTERIC ARTERY SYNDROME. CLINICAL CASE REPORT \\ R.Lukoševičienė, L.Krajevienė, N.Taparauskaitė, E.Krasauskas}

Key words: superior mesenteric artery, duodenum, obstruction, Wilkie syndrome.

Summary

Superior mesenteric artery (SMA) syndrome is a group of symptoms caused by external compression of the third part of the duodenum by the superior mesenteric artery. The prevalence of this syndrome is not well-known but it is diagnosed in $0.013 \%$ $0.3 \%$ of patients with symptoms of intestinal obstruction. Significant weight loss is the most common cause of this syndrome. Compression of the duodenum results in symptoms of the intestinal obstruction - abdominal pain, nausea, postprandial vomiting, early satiety and loss of apetite. The diagnosis of SMA syndrome is confirmed using abdominal CT and MRI. Detection of $\leq 25^{\circ}$ aortomesenteric angle is the most sensitive measure to confirm the diagnosis of SMA syndrome especially when aortomesenteric distance is less than $8 \mathrm{~mm}$. Conservative treatment is usually administered while surgery is the treatment of choice in more severe cases. Full recovery is observed in $90 \%$ of cases. We present a clinical case of a 33-year-old woman who was admitted to the hospital with postprandial abdominal pain, diarrhea, nausea. The symptoms progressed for 2-3 months. Abdominal CT showed possible decrease in aortomesenteric angle and SMA syndrome was suspected.

Correspondence to: ernestas.krasauskas@gmail.com

Gauta 2018-04-16 